\title{
Techno-economic feasibility assessment of life extension decision for safety critical assets
}

\author{
I. Animah, M. Shafiee, N. Simms \\ Cranfield University, Bedfordshire MK43 OAL, United Kingdom \\ M. Considine \\ University of Sheffield, Sheffield S1 3JD, United Kingdom
}

\begin{abstract}
Life extension is one of the major end-of-life decisions in management of the industrial assets which must be made based on all information gathered from system operation and maintenance to ensure that the process is feasible. Most of the existing life extension feasibility assessment models are restricted solely to either "technical" or "economic" considerations, which may lead to inaccurate conclusion or misleading recommendations. In this paper, a techno-economic feasibility assessment framework is developed for life extension decision-making of safety critical assets. All aspects of data collection and review, screening and prioritization of safety critical assets, condition assessment, estimation of remaining useful life and risk analysis are incorporated in the technical assessment. A cost-benefit analysis is also applied to calculate all the costs and benefits of a life extension programme. The decision to qualify an asset for continuous operation beyond its service life is made based on a life extension index which is calculated by combining two indexes of equipment health condition and economic added-value derived respectively from the technical and economic assessments. For the purpose of clarity, the proposed model is applied to a water deluge system on an offshore oil platform.
\end{abstract}

\section{INTRODUCTION}

The increasing demand in world's energy consumption has made life extension (LE) a necessary part of economic life of industrial assets. More than half of the oil and gas installations in the North Sea have exceeded their original design life and now require replacement (Stacey, 2011). The lifespan of a number of nuclear reactors in the United States, United Kingdom and France has been extended by twenty years from 40 to 60 , representing a cumulative capacity of more than 69,000 MW electricity (http://www.eia.gov/).

Nowadays, the engineering systems consist of hundreds of subsystems and components including safety critical elements (SCEs). Even though extending the life of industrial assets can result in economic added-value, the condition of some SCEs may not be suitable for extended operations from safety or environmental perspectives. Thus, the need for development of an appropriate LE management framework for SCEs is crucial. For a successful implementation of the LE management process, a multi-disciplinary decision-making methodology is required to develop. This is because achieving an efficient LE solution requires inputs from designers, system engineers, manufacturers, material specialists, operators and maintenance technicians, health and safety professionals, financial and economic analysts, and human factor researchers. Therefore, the LE management process must be defined taking into account not only economic factors such as maintenance costs, but also technical requirements such as availability and survivability of SCEs during extended period of operation.

Galbraith et al. (2005) developed a capability maturing model (CMM) to assess the technical qualification of offshore installations for LE. Hokstad et al (2010) proposed a framework for LE process integrating material degradation, obsolescence and organisational issues to ensure acceptable technical integrity of offshore assets throughout their life extension period. Vaidya and Rausand (2011) proposed a framework for technical health assessment of critical assets for LE and applied it to a subsea raw seawater injection system. Liu et al (2014) presented a framework for managing LE of the offshore oil and gas installations in Chaina's Bohai 
Bay field. The framework mainly focuses on technical assessment of safety related systems for future operations. Ramírez and Utne (2014) proposes a dynamic Bayesian network for assessing the LE of ageing repairable systems. Adhikary and Kundu (2014) suggested that LE feasibility studies should be based on techno-economic analysis.

Even though the proposed frameworks may be convenient for managers to assess the performance of LE process for SCEs, they have some drawbacks. For instance, they are restricted solely to either "technical" or "economic" considerations which may lead to inaccurate conclusion or misleading solutions to asset managers. Another drawback is that the existing frameworks are one industry specific and may lack applicability outside the industry from which they originate.

The current paper addresses the above-mentioned drawbacks and proposes a generic techno-economic feasibility assessment framework for life extension decision-making based on the asset condition assessment and cost-benefit-analysis (CBA) techniques. The decision to qualify a SCE for continuous operation beyond its service life is made based on a life extension measure (LEM) which is calculated by combining equipment health index (EHI) and economic index (EI) obtained respectively from the technical and economic assessments. The generic nature of the proposed framework makes it applicable to various industries, including the renewable and fossil fuel power generation sectors, railway transport, aerospace, automotive, etc.

The rest of the paper is organised as follows. The techno-economic LE management framework is presented in Section 2. Section 3 applies the proposed framework to evaluate the feasibility of a LE programme for a water deluge system on an offshore oil platform. The research is concluded in Section 4.

\section{TECHNO-ECONOMIC MODEL}

In this Section, a conceptual framework is developed for the purpose of examining LE decisions that are made for SCEs. Most of the information are obtained from a combination of two sources - personal interviews with experts who have experience in undertaking LE programmes, and literature review. As shown in Fig. 1, the proposed framework contains three phases: 1) preparation, 2) assessment, and 3) implementation. The main tasks in each of the phases are described in the following sub-sections.

\subsection{Phase 1: Preparation}

The first phase in the LE management process is the preparation stage which includes the tasks of defining the premises for LE, data collection, and screening and prioritisation of SCEs.

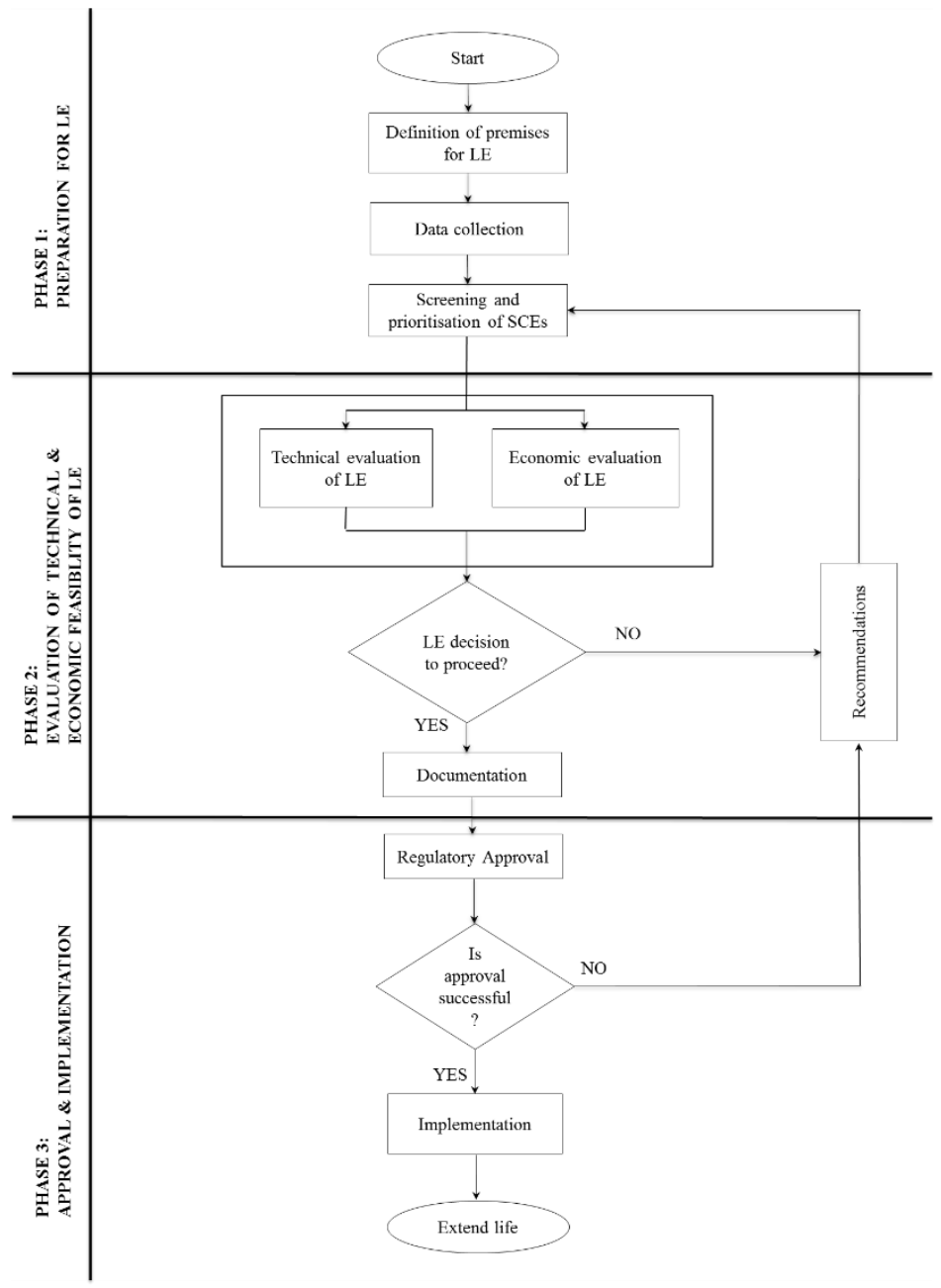

Figure 1. The proposed framework for life extension management of safety critical elements.

\subsubsection{Definition of premises for $L E$}

The LE management process begins with clearly stating the objectives of undertaking such a programme, where these objectives must fit into stakeholders' requirements for the extended operation of assets. Stakeholders for LE programme include regulators/government, operators and investors. Regulators are mostly appointed by governments in many jurisdictions to regulate operators' activities through laws. Non-compliance to these laws may result in sanctions and subsequent invalidation of operational license. Operators and investors also need their installations remain fit-forpurpose throughout their extending lives to maximise return on investment (ROI).

\subsubsection{Data collection}

For an accurate assessment of LE programme, it is necessary to collect data during the design, commissioning, operation, maintenance and modification phases of asset lifecycle. Lack of good quality data will negatively impact the LE decisionmaking procedure. Therefore, appropriate mechanisms should be established to enhance the capabilities of data collection in capital intensive engineering industries and maintain the integrity of assets during extended life of operation. 


\subsubsection{Screening and prioritisation of SCEs}

It might be costly or time consuming to perform LE feasibility analysis on all systems and structures. In this task, the SCEs of an installation asset are systematically identified and prioritized. The main objective of screening task is to focus limited LE management resources on those systems and components whose performance is critical to safety. In addition, the screening and prioritisation of SCEs can substantially improve the reliability and productivity of production facilities in many industries.

Several analytical tools have so far been utilized to screen and prioritise the SCEs, e.g. causeconsequence analysis (CCA), checklist analysis, event tree analysis (ETA), fault tree analysis (FTA), hazard and operability analysis (HAZOP), failure mode and effects analysis (FMEA), failure mode, effects and criticality analysis (FMECA), what-if analysis, etc. This study uses a modified FMEA tool called Ageing Failure Mode and Effects Analysis (AFMEA) for ranking and prioritising the SCEs. The risk priority number (RPN) for potential ageingrelated failure modes are evaluated using 10-point rating scales for severity of impact (S), likelihood of occurrence $(\mathrm{O})$ and likelihood of detection (D). AFMEA is a technique which has been applied in the nuclear energy industry to investigate the ageing effects on critical systems' vulnerabilities (Nitoi et al. 2011). In this paper, we apply the AFMEA technique to identify systems and components possessing high degradation rates. One of the main strengths of this approach is that it allows conducting qualitative and quantitative analyses to evaluate the contribution of SCEs to overall risk of failures in an installation or a system. It is also a structured, sequential and repeatable technique which can be performed using the following steps:

- Breaking the system down into sub-systems.

- Identifying the sub-systems functions.

- Understanding the stress factors for each subsystem and determining possible ageing failure modes.

- Specify detection methods for each possible ageing failure mode.

- Evaluating the risk of each ageing failure mode by assigning indices to $\mathrm{S}, \mathrm{O}$ and $\mathrm{D}$.

- Calculating the RPN by multiplying severity, occurrence and detectability ratings.

- Ranking and prioritising the sub-systems according to their RPN values.

- Making corrective/preventive actions.

The RPN is used to prioritise various failure modes caused by the ageing phenomenon. This number is a value between 1 and 1000, with 1 being the lowest ranking and 1000 the highest. The RPN value represents the effect or contribution of each ageing failure mode to the system's total risk. The assets based on their RPN values are classified into three groups: less sensitive, moderately sensitive and highly sensitive to ageing. In this study, the subsystems having RPN values less than 100 are grouped as less sensitive to ageing and therefore less critical. Sub-systems with RPN values between 100 and 200 are grouped as moderately critical because of their moderate ageing impacts on system safety. Lastly, the sub-systems with RPN values greater than 200 are classified as highly critical.

\subsection{Phase 2: Technical and economic analysis of $L E$}

The second phase of the proposed framework comprises two key modules: (i) technical assessment module which evaluates the equipment's health condition for LE and (ii) economic assessment module which examines the monetary added-value of LE (see Fig. 2). These two modules are explained in details as following:

\subsubsection{Technical assessment module}

The technical assessment module involves the application of condition assessment tools to determine current physical and functional health status of an asset. Risk assessment methodologies have widely been used for this purpose in some industries (see Palkar and Markeset, 2012; Shafiee et al., 2013; Carvalho et al., 2015). On the other hand, probabilistic safety assessment (PSA) models have also been employed in the nuclear industry to determine current health status of safety related systems (Martorell et al., 1999; Kancev et al., 2011; Martón et al., 2015). Prognostic Health Management (PHM) is also gaining prominence in condition assessment and predicting remaining useful life (RUL) of safety related systems. Ramuhalli et al. (2012) applied PHM techniques to predict the RUL of nuclear reactor components. Our proposed framework adopts an assessment rating approach as in references Palkar and Markeset, 2012; Liu et al., 2014; Carvalho et al., 2015. However, the approach utilized in this study is more quantitative and accounts for greater number of factors influencing the LE technical assessment. The steps involved in this approach are described as below:

Step 1: Select one of the SCE's sub-systems based on the screening and prioritisation results.

Step 2: Identify condition assessment factors important to LE assessment of the chosen sub-system.

Step 3: Divide the condition assessment factors into history and health factors according to their risk contributions.

Step 4: Assign a score to each condition assessment factor, as presented in Table 1, based on the available data and the knowledge and experience of field experts or assessment team. 


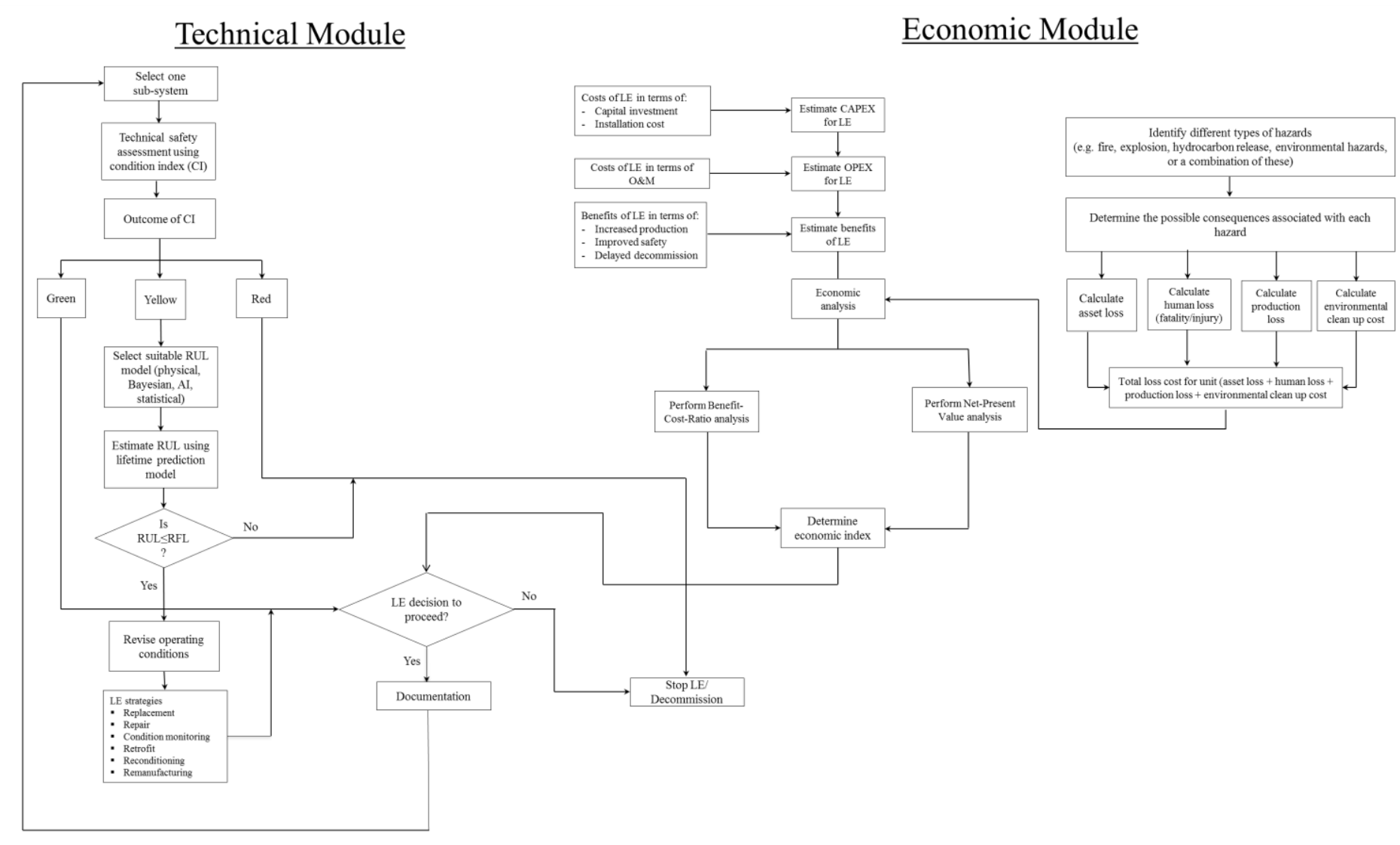

Figure 2. A techno-economic life extension feasibility analysis framework.

Table 1. Rating scores for condition assessment factors

\begin{tabular}{llll}
\hline Rating & Score & Risk level & Condition \\
\hline A & 4 & None & Normal \\
B & 3 & Low & Moderately normal \\
C & 2 & Moderate & Not normal \\
D & 1 & High & Worst \\
\hline
\end{tabular}

Step 5: Sum up the weighted scores for history and health factors to obtain the asset condition score given by Eq. (1):

$$
\text { Condition score }=\sum_{i=1}^{n} S_{i} w_{i} ; \text { where } \sum_{i=1}^{n} w_{i}=1,
$$

where $n$ indicates the number of elements (parameters) taken into account in each factor, $S_{i}$ represents the rating score of the $i$ th element, and $w_{i}$ is the relative importance (weight) of the element $i$.

Step 6: Determine the Condition Index (CI) using Eq. (2) as below:

$$
\mathrm{CI}=0.4 \times \text { history score }+0.6 \times \text { health score. }
$$

Step 7: Display the sub-system's health condition in three colors of green, yellow and red according to the value of condition indices (see Table 2).

Table 2. Asset health condition based upon condition index.

\begin{tabular}{ll}
\hline CI & Asset health condition \\
\hline$[4.0-3.5)$ & Green \\
{$[3.5-3.0)$} & Yellow \\
{$[3.0-0.0)$} & Red \\
\hline
\end{tabular}

Step 8: Estimate the RUL of the sub-system if its health condition is displayed in yellow.
Technical justification of a sub-system for LE is represented by a binary variable (' 0 ' or ' 1 '), where 0 indicates a poor condition and 1 implies a healthy condition. Those sub-systems whose health conditions are displayed in green color will be qualified for LE from technical perspective and their RUL will not require to be estimated. Accordingly, the equipment health index (EHI) is assigned to be one. The red zone represents intolerable risk and those sub-systems that fall into this category are not technically qualified for LE and hence, their EHI is assigned to be zero. If equipment's CI falls in the yellow zone, which is a warning zone, some further measures will need to be taken into account before the sub-system is qualified for LE. In order to assign an EHI for sub-systems in the warning zone, the operator has to determine their RULs.

A review of literature on various methods for estimating the RUL of safety critical systems can be found in Jardine et al. (2006) and Galar et al. (2012). When the RUL of sub-system is estimated, it then is compared to the remaining field life (RFL). If the RUL is less than or equal to RFL, the EHI is assigned as the value one which implies that the sub-system is qualified for LE from technical point of view. Otherwise, when RUL $\leq$ RFL implying that the remaining reserves of the field lack the capacity to implement LE interventions and the process will not be feasible.

Step 9: Repeat process for all sub-systems of the SCE. 


\subsubsection{Economic assessment module}

Even though the technical assessment is key for ensuring safe and reliable operation of SCEs during LE period, the economic evaluation of the programme must not be ignored. The economic assessment accounts for the total investment cost required for implementation of LE strategies. In order to evaluate the economic feasibility of LE programme, an economic index (EI) on the basis of cost-benefit-analysis (CBA) is presented. According to Mechler and Hochrainer-Stigler (2013), CBA compares the cost of implementing an alternative with its benefits and then calculates the net economic efficiency. In order to perform an economic analysis for LE, the decision-makers must first identify the benefits and costs associated with LE.

\subsubsection{Benefits of $L E$}

The benefits of extending the service life of SCEs usually include: increased production, improved safety and delayed decommissioning cost (continued license to operate) (Shafiee and Zuo, 2012). Increased production is interpreted as the ability to reduce the equipment downtime which can be achieved through either improving the fault detection capability or reducing the maintenance lead times. Another benefit associated with LE is increased revenue generation, since an increase in the level of production leads to larger revenue streams.

Improved safety involves the benefits that arise from reduction of fatalities as a result of implementing LE programme. However, these benefits are often non-monetary and it is difficult to quantify them. It has been proven in the literature that when assets reach their end-of-life stage (i.e., the third stage of the bathtub curve), they typically experience an increasing failure rate. So, extending the service life when an appropriate LE strategy is adopted has the potential to reduce the equipment failure rate. It is also an established fact that extending the service life of SCEs will delay commissioning costs to be incurred, which can be considered as an added-value to assets managers.

\subsubsection{Costs of $L E$}

The costs associated with LE process include capital investment, installation cost and operating expenses. The capital investment costs for LE consist of cost of acquiring new equipment and the cost of hardware and software upgrades for SCEs to achieve an appreciable level of safety which is a requirement for license application. Installation of newly acquired equipment requires hiring and paying a number of laborers. In addition, the installation of new equipment may require some facilities to be shut down for a period of time, resulting in production loss penalties. Furthermore, a number of service boats must be used for transportation of LE personnel, equipment and consumables to and from installations.
Operating expenditures consist of all operating expenses including maintenance cost, royalty cost, logistical support cost (e.g. spare part cost) and statutory taxes for the extended operation.

Finally, the economic index (EI) can be determined using Net Present Value (NPV) or Benefit-Cost-Ratio (BCR) techniques. These techniques are briefly summarized as below:

\section{Net Present Value (NPV)}

NPV is defined as the difference between the present values of benefit cash flows and cost cash flows over a period of time. In order to compute the NPV of a LE strategy, the below equation is used:

$$
\mathrm{NPV}=\sum_{t=0}^{T} \frac{1}{(1+r)^{t}}[B(t)-C(t)]
$$

where $B(t)$ and $C(t)$ represent respectively the total benefits and costs in a given year $t, r$ is the discount rate and $T$ is the time horizon of LE programme. If the NPV for a LE solution is non-negative (i.e., NPV $\geq$ 0 ), then the EI is assigned to be one; otherwise, if NPV $<0$, the index is assigned as zero.

\section{- Benefit-Cost Ratio (BCR)}

BCR is defined as the present value of all benefits divided by present value of all costs. Therefore,

$$
\mathrm{BCR}=\sum_{t=0}^{T} \frac{B(t)}{(1+r)^{t}} / \sum_{t=0}^{T} \frac{C(t)}{(1+r)^{t}} .
$$

Now, if the BCR for a LE solution is greater than or equal to one (i.e., $\mathrm{BCR} \geq 1$ ), then the $\mathrm{EI}$ is assigned to be one; otherwise, if $\mathrm{BCR}<1$, the index is assigned as zero.

The economic assessment module in the second phase of our proposed framework uses a risk-cost assessment approach to calculate the risks/costs associated with LE programme. The total risk-cost (TRC) includes four types of risks/costs arising due to asset loss (ALRC), human health loss (HHLRC), environmental damage (EDRC), and production loss (PLRC). Therefore,

$$
\mathrm{TRC}=\mathrm{ALRC}+\mathrm{HHLRC}+\mathrm{EDRC}+\text { PLRC } .
$$

These four types of risks/costs are described below in details:

\section{Asset loss risk-cost (ALRC)}

Asset loss risk-cost refers to the costs incurred due to loss of equipment or damage to equipment as a result of ageing phenomenon. Ageing effects on SCEs may lead to major accidents such as fire and explosion. ALRC can be calculated using Eq. (6) given by:

$$
\mathrm{ALRC}=\mathrm{A}_{\mathrm{D}} \times \mathrm{C}_{\mathrm{A}},
$$

where $A_{D}$ represents the equipment's damage area and $\mathrm{C}_{\mathrm{A}}$ is the asset loss cost per unit area.

\section{- Human health loss risk-cost (HHLRC)}

Human health loss risk-cost is calculated by the product of the number of people that may be affected 
$\left(\mathrm{N}_{\mathrm{D}}\right)$ and the health care cost associated with each fatality $\left(\mathrm{C}_{\mathrm{H}}\right)$. Thus,

$$
\text { HHLRC }=\mathrm{N}_{\mathrm{D}} \times \mathrm{C}_{\mathrm{H}} .
$$

The cost of human fatalities may introduce a degree of uncertainty into the cost calculations. Khan and Amyotte (2005) suggested that some indicators such as cost of rehabilitation, insurance and worker's compensation rate can be used instead.

\section{- Environmental damage risk-cost (EDRC)}

Environmental damage risk-cost includes cost of all kinds of damage to operating environment and surface cleaning charges, if required. Then,

$$
\mathrm{EDRC}=\left(\mathrm{A}_{\mathrm{ED}} \times \mathrm{C}_{\mathrm{ED}}\right)+\mathrm{C}_{\mathrm{SC}},
$$

where $A_{E D}$ represents environment's damage area, $\mathrm{C}_{\mathrm{ED}}$ is the cost of environmental damage per unit area, and $\mathrm{C}_{\mathrm{SC}}$ represents the surface clean-up cost.

\section{- Production loss risk-cost (PLRC)}

Production loss risk-cost due to asset damage is calculated by the production rate per day $\left(\mathrm{C}_{\mathrm{P}}\right)$ multiplied by expected downtime $\left(\mathrm{T}_{\mathrm{d}}\right)$ in days. Then,

$$
\mathrm{EDRC}=\mathrm{C}_{\mathrm{P}} \times \mathrm{T}_{\mathrm{d}} .
$$

Finally, the life extension measure (LEM) is determined by multiplying equipment health condition index and economic added-value index. If LEM equals one, the sub-system will be qualified for LE from both technical and economic perspectives.

\subsection{Phase 3: Approval and implementation}

The third phase of the proposed framework focuses on regulatory approval process and implementation of measures to monitor the effectiveness of LE management programme.

\subsubsection{Regulatory approval}

LE programme must be supported by engineering and technical documentation for justification of continuous operation of SCEs beyond their original design life. The main purpose of regulatory consideration and approval is to thoroughly assess the documentation submitted by operators and ensure that SCEs can perform their intended functions during LE period in accordance with relevant regulations. Regulators are required to review and verify that LE programme is consistent with current regulations and industry-approved standards. In the case when a SCE is not qualified for LE at the approval stage, a recommendation is made whether or not to decommission the facilities.

\subsubsection{Implementation}

This task of the framework provides the expected main outputs from the proposed LE management programme enabling optimisation and continuous improvement of testing, inspection and maintenance actions required during extended life period.

\section{APPLICATION AND RESULTS}

In this Section, the proposed model is applied to support the LE decision-making for a water deluge system on an offshore oil platform. The platform was commissioned in 1990 for producing oil and gas from the West African region. The platform is a tanker based floating production and storage (FPSO) facility and its water deluge system is expected to be operated for an extended length of time, up to seven years.

The water deluge system on the platform has been designed and constructed according to ISO standards and guidelines as described in the company's engineering documents. The sub-system of the water deluge system consists of seawater (SW) lift pump and booster pump packages with diesel power directdriven system. The diesel engine drive system was replaced by a new one 10 years ago. The water deluge system is independent of SW cooling system and according to the inspection of piping and instrument data (P\&ID), it is also independent of all other systems on the platform. An illustration of the water deluge system is presented in Fig. 3. Other subsystems include: fire and gas $(F \& G)$ logic, nozzles, detectors, firewater (FW) ring main, pipes, controls, instrumentation and valves used for various purposes.

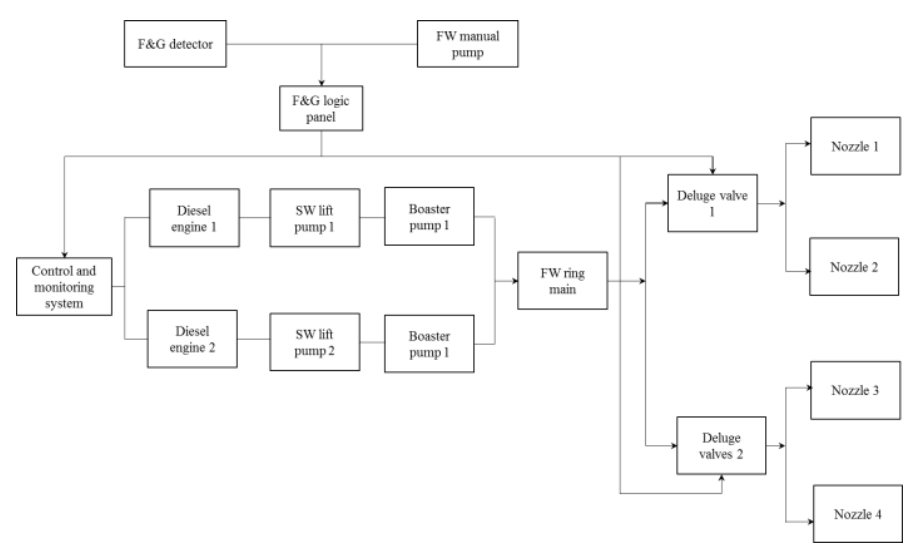

Figure 3. The sub-systems of a water deluge system

In Fig. 3, the arrows illustrate the direction of the water flow. The seawater is pumped at a height of $80 \mathrm{~m}$ by the lift pump. The water then flows through the booster pump to the FW ring main for distribution. In addition, $55 \mathrm{~m}^{3} / \mathrm{h}$ of water is used for diesel engine cooling. The FW ring main is fitted with check valves to avoid back flow to the pumping system. FW ring main piping are situated outside of hazardous areas to use for multi-directional flow. There is a F\&G logic which is responsible for starting diesel engine and pumps as well as opening of deluge valves at the alarm from detectors. According to the information collected from design manuals, the water deluge system is constructed from materials such as $\mathrm{Cu} / \mathrm{Ni}(90 / 10)$ alloy for pumps and diesel engine cooling system and galvanised carbon steel for the piping network. In what follows, the results of the case study are presented and discussed. 


\section{- Premise for LE}

The objective of this study is to extend the life of water deluge system for future operations.

\section{- Data collection}

The information required for analysis was collected from design, operation and maintenance manuals as well as other internal documents.

\section{- Screening and prioritisation of SCES}

The results of the screening and prioritisation process are presented in Table 3. AFMEA revealed that the failure modes of each sub-system are mainly caused by ageing phenomenon. Based on the RPN values obtained from AFMEA, all sub-systems were ranked and prioritised for detailed analysis. However, the assessments focused on sub-systems with RPN values greater than 200 .

Table 3. Selected SCEs for LE assessment and analysis.

Safety critical element: Water Deluge System

\begin{tabular}{lll}
\hline Sub-system & $\begin{array}{l}\text { Risk level with } \\
\text { respect to ageing }\end{array}$ & $\begin{array}{l}\text { Number of sub- } \\
\text { systems in SCE }\end{array}$ \\
\hline SW pump & High & 2 \\
Piping & High & 35 \\
Diesel engine & Moderate & 2 \\
F\&G logic & Moderate & 1 \\
\hline Total & & 40 \\
\hline
\end{tabular}

\section{- Techno-economic assessment}

Current health status of sub-systems and economic implications of selected LE strategies were assessed. The results for the techno-economic assessment are presented in Table 4.

Table 4. Results of the techno-economic LE assessment

\begin{tabular}{lccccccc}
\hline \multirow{2}{*}{ SCE } & CI & RUL & BCR & NPV & EHI & EI & LEM \\
& & yrs. & & $\$$ & & & \\
\hline SW & 3.3 & 4 & 3.13 & 7615.50 & 1 & 1 & 1 \\
pump & & & & & & & \\
Pipings & 1.6 & - & 0.60 & -1406 & 0 & 0 & 0 \\
$\begin{array}{l}\text { Diesel } \\
\text { engine }\end{array}$ & 3.9 & - & 2.1 & 3120 & 1 & 1 & 1 \\
$\begin{array}{l}\text { F\&G } \\
\text { logic }\end{array}$ & 3.7 & - & 2.34 & 4800.39 & 1 & 1 & 1 \\
\hline
\end{tabular}

Results of the technical assessment indicate that the F\&G logic has CI of 3.7 and is qualified for LE programme from technical perspective. This means that existing maintenance and ageing management programmes can be applied to manage the $F \& G$ system deterioration during extended life operation. The economic assessment indicated that the NPV for $\mathrm{LE}$ of $\mathrm{F} \& \mathrm{G}$ logic is greater than zero and BCR $>1$, hence assigning an EI of value 1.

The analysis for the diesel engine drive system produced a CI of 3.9 and a positive NPV value as well as a BCR value greater than one. Therefore, it is qualified for extended operations.
The CI for SW lift pump is evaluated as 3.3, implying that the condition of sub-system is displayed in yellow color (i.e., the warning zone). The value of EHI is assigned to be 1, because the RUL of subsystem from available data is estimated to be four years which is less than the RFL of seven years. This indicates that the oil field has still this potential to be considered for LE intervention, i.e. replacement, remanufacturing, reconditioning, etc. Also, the economic assessment shows an NPV of $\$ 7615.50$ and a BCR value of 3.13, meaning that LE for the SW lift pump will result in substantial economic benefits to asset operators.

Technical assessment of piping network produced a CI of 1.6, indicating that the sub-system is not technically qualified for extended operations. Moreover, its economic assessment produced a negative NPV and a BCR value less than one.

In overall, based on the LEM values given in Table 4, the F\&G logic, SW pump and the diesel drive system are qualified for LE. Even though three (out of four) of critical sub-systems have LEM of value 1, the entire water deluge system cannot be qualified for LE management programme because the LEM for the piping network is zero. Hence the overall system is still considered unsafe for extended operations. For this reason, the asset managers must first implement corrective/preventive actions on sub-system piping network so that its LE also becomes feasible from both technical and economic perspectives, then the LE programme for the whole system can be proceed.

\section{CONCLUSIONS}

In this paper, a techno-economic feasibility assessment framework was developed for life extension (LE) decision making of safety critical assets. The proposed framework provides a powerful decision-making tool for assessing and qualifying the SCEs for LE on the basis of asset condition assessment and cost-benefit-analysis (CBA). For the purpose of clarity, the efficacy of the proposed framework was shown through an application to LE decision-making of a water deluge system in the offshore oil and gas industry. The results of the application case study demonstrated the validity of the proposed framework for LE process. This study also overcame the shortcomings of available LE decision models which are restricted solely to either technical or economic considerations. The proposed framework provides decision-makers opportunity to incorporate simultaneously technical and economic issues when evaluating LE strategies.

The proposed framework will be applied in the future to critical structures operating in other industries. Development of mathematical models to jointly determine the optimal LE interval and associated maintenance strategy can be another area 
of research. Since economic losses due to safety and environmental damages cannot easily be quantified, thus introducing uncertainties into economic analysis. Appropriate tools can be developed to reduce uncertainty involved in the risk cost model. Also, computerised systems and processes must be developed to ensure that good quality data is available for LE assessment.

\section{REFERENCES}

Adhikary, P. and Kundu, S. (2014) Renovation modernization uprating \& life extension: optimal solution for small hydropower development. International Journal of Engineering Science \& Advanced Technology, 4(3), 300306.

Carvalho, E., Tang, F., Allen, E. and Sharma, P. (2015) A case study of asset integrity and risk assessment for subsea facilities and equipment life extension. In: Offshore Technology Conference, Houston, Texas, USA, May 04-07, pp. 1-12.

Galar, D., Kumar, U., \& Fuqing, Y. (2012). RUL prediction using moving trajectories between SVM hyper planes. In Reliability and Maintainability Symposium (RAMS), 2012 Proceedings-Annual (pp. 1-6). IEEE.

Galbraith, D.N., Sharp, J.V. and Terry, E. (2005) Managing life extension in aging offshore installations. In: International Petroleum Exhibition and Conference, Aberdeen, 2005, pp. $1-8$.

Hokstad, P., Habrekke, S., Johnsen, R. and Sangesland, S. (2010) Ageing and life extension for offshore facilities in general and for specific systems SINTEF Technology and Society, Report no. A15322, Trondheim, Norway.

Jardine, A. K. S., Lin, D., \& Banjevic, D. (2006). A review on machinery diagnostics and prognostics implementing condition-based maintenance. Mechanical Systems and Signal Processing, 20(7), 1483-1510.

Liu, H., Shi, X., Chen, X. and Liu, Y. (2014) Management of life extension for topsides process system of offshore platforms in Chinese Bohai Bay. Journal of Loss Prevention in the Process Industries, 35, 357-365.

Kancev, D., Gjorgiev, B., \& Cepin, M. (2011). Optimization of test interval for ageing equipment: A multi-objective genetic algorithm approach. Journal of Loss Prevention in the Process Industries, 24(4), 397-404.

Khan, F. I., \& Amyotte, P. R. (2005). I2SI: A comprehensive quantitative tool for inherent safety and cost evaluation. Journal of Loss Prevention in the Process Industries, 18(46), 310-326.

Martorell, S., Sanchez, A. and Serradell, V. (1999) Agedependent reliability model considering effects of maintenance and working conditions. Reliability Engineering and System Safety, 64(1), 19-31.

Martón, I., Sánchez, A. I., \& Martorell, S. (2015). Ageing PSA incorporating effectiveness of maintenance and testing. Reliability Engineering \& System Safety, 139, 131-140.

Mechler, R., \& Hochrainer-Stigler, S. (2013). Probabilistic costbenefit analysis of disaster risk management in a development context. Disasters, 37(3), 374-400.

Nitoi, M., Turcu, I., Bruynooghe, C. and Pavelescu, M. (2011) Prioritization of components important for safety and sensitive to ageing. Application for TRIGA reactor. Progress in Nuclear Energy, 53(4), 336-343.
Palkar, S. and Markeset, T. (2012) Extending the service life span of ageing oil and gas offshore production facilities. Advances in Production Management Systems. Value Networks: Innovation, Technologies, and Management, Volume 384 of the series IFIP Advances in Information and Communication Technology, pp. 213-221.

Ramírez, P.A.P. and Utne, I.B. (2014) Use of dynamic Bayesian networks for life extension assessment of ageing systems. Reliability Engineering and System Safety, 133, 119-136.

Ramuhalli, P., Coble, J., Meyer, R. M., \& Bond, L. J. (2012). Prognostics health management and life beyond 60 for nuclear power plants. In Future of Instrumentation International Workshop (FIIW), 2012 (pp. 1-4).

Shafiee, M. and Zuo, M.J. (2012). Adapting an age-reduction model to extend the useful-life duration. In: International Conference on Quality, Reliability, Risk, Maintenance, and Safety Engineering, Chengdu, China, 15.6.2012 - 18.6.2012.

Shafiee, M., Finkelstein, M. and Zuo, M.J. (2013). Optimal burn-in and preventive maintenance warranty strategies with time-dependent maintenance costs, IIE Transactions, 45(9), 1024-1033.

Stacey, A. (2011) KP4: Ageing \& life extension inspection programme-The first year. In: Proceedings of 30th International Conference on Ocean, Offshore and Arctic Engineering (OMAE), Rotterdam, The Netherlands, June 19-24, pp. 38-44.

Vaidya, P. and Rausand, M. (2011) Remaining useful life, technical health, and life extension. Proceedings of the Institution of Mechanical Engineers, Part O: Journal of Risk and Reliability, 225(2), 219-231. 